\title{
The Effect of Monolingual and Bilingual Dictionary on the Foreign Language Learners' Acquisition
}

\author{
Nada Mohsin Aboghunaim \\ Department of English, University of Kufa, Najaf, Iraq \\ Email address: \\ nadam.taher@uokufa.edu.iq \\ To cite this article: \\ Nada Mohsin Aboghunaim. The Effect of Monolingual and Bilingual Dictionary on the Foreign Language Learners' Acquisition. \\ International Journal of Applied Linguistics and Translation. Vol. 5, No. 4, 2019, pp. 55-57. doi: 10.11648/j.ijalt.20190504.11
}

Received: September 8, 2019; Accepted: September 25, 2019; Published: October 11, 2019

\begin{abstract}
Dictionaries have traditionally been a widely used tool by foreign and second language learners. In spite of the rejection of using dictionaries in classroom by some teachers, recent studies have showed that dictionaries play a vital role in language learning and teaching. The purpose of this study is to explore the effect of both monolingual and bilingual dictionaries on the foreign language learners' awareness and acquisition. The study seeks to investigate that monolingual dictionaries, unlike bilingual dictionaries, would promote and assist learners' acquisition. Although bilingual dictionaries are universally preferred by learners, teachers' duty here is to encourage students to consult monolingual dictionaries during classroom since they often expose to the foreign language which is the end. Thus, the research will highlight the pros and cons of both monolingual and bilingual dictionaries. It will focus on the teachers' role which is crucial on not only guiding learners how to use dictionaries, when and which type but also allocating time during classroom to encourage students to consult the dictionary in order to be familiar with this tool. Finally, the striking findings are both dictionaries have positives and negatives but the good teacher can guide his/her students to consult the appropriate one in the specific time and a suitable task in classroom. Dictionaries are not always the perfect tool used by students and teachers but there are some cases and situations teachers should take in consideration when they deal with dictionaries.
\end{abstract}

Keywords: Monolingual Dictionaries, Bilingual Dictionaries, Learners' Acquisition, Foreign Language Learners

\section{Introduction}

Dictionaries in general are often seen as a powerful pedagogical device in the process of foreign language learning. A wide range of studies are conducted regarding using dictionaries in order to learn a foreign language. [1-5] However, it has been still a controversial issue to decide which kind of a dictionary students should consult.

This paper will investigate the crucial role of dictionaries that promote teaching strategies and develop linguistic skills. In this regard, a dictionary can be seen as an authentic source of knowledge in the foreign language learners' classes.

Dictionaries are first manifested to meet the need of native speakers as oxford English dictionary. Then, they have been modified to be used by millions of English learners around the world. [4]

A dictionary can be divided into three kinds: monolingual (MD), bilingual (BD), and bilingualized. [4] This paper will shed light on the first two types, i.e. monolingual and bilingual dictionary and to what extent they can enhance foreign language and promote acquisition. Besides, the study seeks to answer whether monolingual dictionary is the best dictionary in terms of language acquisition or not and why.

\section{Literature Review}

Although dictionaries are seen as a basic tool in the process of foreign language learning for some teachers, some teachers believe that dictionaries hinder language learning. They can waste the time during lessons. [2]

The idea of using dictionaries in the classroom was rejected for a long time, as Thornbury puts, due to many reasons. First, it was thought that it hinders guessing skills from context. Second, learners tend to spend more time on translation if the dictionary is bilingual. [6] However, a range of studies and surveys show the influence of using dictionaries in teaching and learning language especially 
vocabulary. [6-9] Lew \& Adamska-Salaciak add that dictionaries encourage learner autonomy. [5]

Some studies reveal that students who use dictionaries obtained higher scores than students who did not, even though those candidates spent twice as long to read the passage as learners who did not use a dictionary. Students who do not cope with guessing strategies depend on dictionaries in order to help learning vocabulary. The use of dictionaries, in this case, will be useful for them. [1]

According to Nation and Lew \& Adamaska-Salaciak, there are three types of dictionaries: monolingual dictionaries (MDs), such as Collins Cobuild English dictionary and Oxford English dictionary for learners in which a word entry, definitions and examples are written in one language. The second type is bilingual dictionaries (BDs) such as wordreference and AL-Mawrid in which two languages are used and they often have two directions-L1-English and English-L1. Bilingualized dictionaries are the third type which are known as semi-bilingual dictionary. The choice of which dictionary is the best reference tool in learning vocabulary is a controversial issue. Some teachers recommend MDs over BDs. While others propose BDs. In fact, each kind of dictionary can be used in a way that is different from others and has positives or negatives. Let us consider the features of each type. $[5,8]$

\subsection{Monolingual Dictionaries}

First, MDs will be discussed. Nation identifies that English learners use monolingual dictionaries so as to interpret the definition, examples and the word forms. [8] The advantages of MDs, as Baxter presents, can be said that they promote the ability of paraphrasing among learners as they would realize the definition in the context. BDs, however, discourage this ability since students realize that meaning can be expressed by a single word. Another factor to be considered is that the best monolingual dictionaries provide a wide range of lexical information (i.e. noun countability, collocation, idioms, examples, derivations). In this regard, learners will expose to the knowledge and they can unconsciously acquire language effectively. [5]

Nevertheless, there are many challenges encounter foreign learners. First, learners are required to know how they look up the correct entry in order to benefit from this wealth of data since the entry is written in the L2 [5]. In this case, MD attempts to entirely eliminate learners from their L1. Less proficient students, then, would have negative attitude towards MDs since they would face difficulty to understand the definitions, the symbols and morphological information in the foreign language $[1,2]$. Wingate also criticizes MDs because MD tends not to be useful for learners if it is used for production purposes since learners cannot find the item they are looking up for. [11]

\subsection{Bilingual Dictionaries}

The second type is bilingual dictionary. According to a survey conducted, learners admit that though MDs provide more precise and detailed information than BDs, learners prefer bilingual dictionaries that start with L2 in finding unknown words. The reason for this lies in the fact that unclear words in defining the entry word force learners to an additional search. Further, the lack of direct reference to L1 in MDs results in disregarding this type of dictionary. Thus, L2-L1 dictionaries provide easy access for students to understand the materials they read [12].

Turning to the positives of BDs, they offer meaning in an accessible way and has two directions-L1-English and English-L1. Additionally, students seem to use them for productive use (writing and speaking). On the other hand, the negatives of MDs are that they use a controlled vocabulary in defining the meaning of a word entry. Thus, learners are required to be familiar with this vocabulary and grammatical difficulties. MDs lack the feature of BDs that BDs provide simple access to vocabulary for productive use $[6,8]$.

A number of researchers criticise BDs for promoting translation that is thought to be a drawback feature in classroom. That is to say, BDs encourage the belief that words in L1 and L2 are equivalent in meaning and they provide little information on the using of words [8]. Another drawback is stated by Baxter which is BDs discourage learners from thinking in the target language. In this regard, learners would not develop their linguistic skills such as paraphrasing. [10]

To improve a dictionary then, researchers, suggest using bilingualized dictionaries since they believe that they provide a variety of look up possibilities and personal references. One of the advantages of this dictionary is that it combines the information of both MDs and BDs. However, it has negatives. Unidirectionality from the target language is one of its weaknesses. Learners, then, need to be familiar with L2 word form so as to look up for necessary information. [12]

\section{Conclusion}

To conclude, a dictionary is an indispensable tool in the learning process. It was worth noting that neither MD nor BD is perfect in itself. Both of them are complementary to each other. Both have positives and negatives. In this regard, some researchers and teachers recommend that in order to gain effective use of a dictionary learners need to use both monolingual dictionaries (MDs) and bilingual dictionaries (BDs) to obtain adequate and reliable information though using two dictionaries is considered time-consuming and rather tedious [8, 12]. Furthermore, it should be clear now that MDs are useful for upper intermediate and advanced learners. Teachers should devote time to consult dictionary during classes whenever applicable. They should guide and encourage learners and recommend them to use MD in order to think in the foreign language which is the end of each teacher and student. Rich information and wealth date given by $\mathrm{MD}$, unlike $\mathrm{BD}$, would help them acquire language effectively. 


\section{Pedagogical Implication}

According to the crucial role that vocabulary plays on learning and teaching foreign language, the use of dictionary is considered as one method to deal with vocabulary. [7]

Teachers, especially non-native speakers, involve with dictionaries to confirm their knowledge and when they construct exercises. Teachers should teach their students how and when to use dictionaries. Teachers could guide learners to use a dictionary after they teach them a phonemic transcript, grammar codes to promote the easy and effective use of a dictionary as well as quick search for the word alphabetically. Teachers, also, have to encourage guess first and if it does not work, they ask learners to move to consult dictionaries and to enhance discussion concerning the problems that arise from looking up the dictionary to solve it [13].

One of the methods to enforce learners to look up the word is that, as Laufer (as cited in [7]) believes, when learners encounter words which are familiar to him but the context is not, learners then are encouraged to consult the dictionary.

Surveys show that although both MDs and BDs have an impact on teaching vocabulary, BDs result in a high reading speed. Due to the lack of learners' awareness concerning using dictionaries effectively, materials developers should include tasks which demand looking up the meaning of a word from a dictionary in order that students could familiarize with dictionary use.

However, it can be concluded that using dictionaries need to be limited to specific situations since it is not suitable for every reading activities nor every single word unknown by students. Students are encouraged to infer first unknown words then they consult the dictionary if these words cannot be easily inferred.

\section{References}

[1] Hayati, A. M. \& Pour-Mohammadi, M. (2005). A comparative study of using bilingual and monolingual dictionaries in reading comprehension of intermediate EFL students. The reading Matrix, 5 (2), 61-66.
[2] Holi Ali, H. I. (2012). Monolingual dictionary use in an EFL context. English language teaching, 5 (7), 2-7.

[3] Marmol, G. \& Sanchez-Lafuente, A. (2013). The bilingual dictionary and foreign language learning: facts and opinions. Porta Linguarum, 20, 89-101.

[4] Al-Sayed, A. \& Siddiek, A. (2013). Monolingual and bilingual dictionaries as effective tools of the management of English language education. Theory and practice in language studies, 3 (10), 1744-1755.

[5] Lew, R. \& Adamska-Salaciak, A. (2015). A case for bilingual learners' dictionaries. ELTJournal, 69 (1), 47-57.

[6] Thornbury, S. (2002). How to teach vocabulary. Harlow: Longman.

[7] Hayati, M. \& Fattahzadeh, A. (2006). The effect of monolingual and bilingual dictionaries on vocabulary recall and retention of EFL learners. An International Online Journal, 6 (2), 15-134.

[8] Nation, I. S. P. (2013). Learning vocabulary in another language. Cambridge: Cambridge University Press.

[9] Shamshirian, M. (2015). Assessing the effect of utilizing monolingual and bilingual dictionaries on EFL learners' vocabulary. Language in India, 15 (7), 175-188.

[10] Baxter, J. (1980). The dictionary and vocabulary behavior: A single word or a handful? TESOL Quarterly 14 (3): 325-336.

[11] Wingate, U. (2002). The effectiveness of different learner dictionaries. An investigation into the use of dictionaries for reading comprehension by intermediate learners of German. Lexicographica Series Maior: Tübingen Niemeyer.

[12] Laufer, B. \& Levitzky-Aviad, T. (2006). Examining the effectiveness of bilingual dictionaries plus a dictionary for production in a foreign language. International of Lexicography, 190 (2), 135-155.

[13] Schmidtt, N. \& McCarthy, M. (1997). Vocabulary: description, acquisition, pedagogy. Cambridge: Cambridge University Press. 